\title{
Transmisión e interpretación del Nuevo Testamento. Diálogo desde la traducción
}

\author{
Juan Chapa \\ FACUlTAD DE TEOLOGÍA UNIVERSIDAD DE NAVARRA \\ jchapa@unav.es
}

Resumen: Uno de los riesgos del quehacer teológico es querer "domesticar" el texto bíblico, asumiendo inconscientemente que disponemos de los autógrafos originales. El método histórico-crítico y en concreto la crítica textual como su punto de partida sirve de recordatorio permanente para evitar caer en esa trampa. La "Nueva Filología”, la cultura manuscrita y las nuevas aproximaciones a la crítica textual neotestamentaria muestran que ante la imposibilidad de alcanzar el texto original necesitamos de cada uno de los manuscritos como testimonios de un texto "siempre vivo". Las traducciones latinas son un ejemplo de esta vitalidad. Manifiestan cómo el texto escapa todo reduccionismo y no es separable de la comunidad de fe en que ha nacido.

Palabras claves: Nuevo Testamento, Nueva Filología, Crítica textual, Traducciones latinas.

Abstract: One of the risks of the theologian is the desire of "domesticating" the biblical text, assuming unconsciously that we have the original autographs. The historical-critical method and, specifically, textual criticism as its starting point, functions as a permanent reminder to avoid falling into this trap. The "New Philology", the culture manuscript and the new approaches to New Testament textual criticism show that in the impossibility of reaching the original text we need to analyse each of the manuscripts as testimonies of a "living text". Latin translations are an example of this vitality. They manifest how the text escapes reductionism and cannot be separated from the community of faith in which it is born. Keywords: New Testament, New Philology, Textual Criticism, Latin Translations. 
En 1990, la revista Speculum, editada por la Medieval Academy of America, publicó un número dedicado por entero a la llamada "Nueva filología"1. Esta tendencia de la filología románica que algunos prefieren denominar "filología material" o "textualidad social" -y a la que no le han faltado críticas $^{2}$ - propone introducir una nueva visión del texto medieval, siguiendo las huellas de un ensayo publicado por Bernard Cerquiglini que lleva por título Éloge de la variante ${ }^{3}$. Según la tesis fundamental de este filólogo francés influenciado por Michel Foucault y Jacques Derrida, los críticos no deben reducir la tradición medieval a un único texto, sino que han de permitir que la variación coexista. La razón de ello es que, como señala Cerquiglini un tanto provocativamente, "la escritura medieval no produce variantes; ella misma es variación"4. Es decir, en lugar de mirar las variantes como desviaciones de la norma, Cerquiglini sostiene que hay que verlas como productos naturales de la cultura de los escribas, una cultura en la que las diversas lecturas no deben ser consideradas excepciones a la regla o corrupciones de un texto sino la norma misma.

Con todo, cuando en 1990 se acuñó el término, la Nueva Filología no era tan novedosa. Tenía sus precedentes en otros autores de diversas épocas y de manera particular en la obra del crítico literario y filólogo suizo Paul Zumthor, quien, en los años setenta y también en el ámbito de la medievalística, realzó la importancia de la fluidez de los textos. A esta fluidez Zumthor denominó mouvance, que ha pasado a ser utilizado como término técnico en lengua francesa para describir los niveles de

1 Fue editada por S. G. Nichols, "Introduction: Philology in a Manuscript Culture", en Speculum 65 (1990) 1-10. En p. 9 señala que la novedad radica en "the insistence that the language of texts be studied not simply as discursive phenomena but in the interaction of text language with the manuscript matrix and of both language and manuscript with the social context and networks they inscribe". Ver también Susan Yager, "New Philology", en A. Classen (ed.), Handbook of Medieval Studies: Terms Methods - Trends, vol. 1 (De Gruyter, Berlin-New York 2010) 999-1006.

2 Ver por ejemplo A. Varvaro, “The «New Philology» from an Italian Perspective", en Text: An Interdisciplinary Annual of Textual Studies 12 (1999) 49-58.

3 B. Cerquiglini, Éloge de la variante: Histoire critique de la philologie (Seuil, Paris 1989).

4 B. Cerquiglini, Éloge de la variante..., 111. 
variación textual y movilidad entre manuscritos ${ }^{5}$. Zumthor define mouvance como un producto de continuo cambio y una interferencia entre diversas tradiciones, tanto orales como escritas. Consecuentemente, rechaza la preferencia por el "mejor manuscrito" (es decir, aquel que refleja fielmente un momento decisivo en la tradición textual más temprana) y, al abandonar la preferencia por un testigo único, afirma que lo que interesa es la suma total de todas las versiones, incluyendo no solo las que sobreviven desde tiempos medievales sino también las ediciones más modernas. En todo caso, defiende que la primera versión ya no tiene prioridad; todas las versiones posteriores pueden ser potencialmente comparables con esta por cuanto tienen un valor documental en el continuo desarrollo del texto en el acto de hacerse a sí mismo ${ }^{6}$, a través del proceso de lectura-escuchacopia que se da a lo largo de los siglos?

Al margen de los muchos flancos discutibles que presenta, la Nueva Filología ha servido para ampliar el ámbito de la crítica textual tradicional que buscaba recuperar la forma auténtica de un texto a partir de los manuscritos disponibles, tanto en conformidad con el método de Lachmann (método estemmático) como el de Bédier (la opción del mejor manuscrito). La nueva corriente subraya que la preocupación por lograr un texto original y presentarlo como "el texto" está reñida con la variedad de manuscritos y copias que conservamos. Cada uno de estos manuscritos es único y por eso ni la variación ni la falta de conformidad o "rebeldía" (unruliness) de los textos se pueden disociar de esos manuscritos. De ahí que haya que dar una mayor relevancia a las variantes en lugar de "esconderlas" o "encerrarlas" en un aparato crítico como en una cárcel". Se pasa de un afán de búsqueda del texto original a una nueva manera de editar y estudiar las tradiciones textuales inestables.

$5 \quad$ P. Zumthor, Essai de poétique médiévale (Éditions du Seuil, Paris 1972; ${ }^{2} 2000$ ). Ver R. Rosenstein, "Mouvance”, en A. Classen (ed.), Handbook of Medieval Studies..., 1538.

6 P. Zumthor, Essai de poétique médiévale..., 73.

7 R. Rosenstein, "Mouvance...", 1540.

$8 \quad$ B. Cerquiglini, Éloge de la variante..., 106. 


\section{Cultura manuscrita y texto fluido}

Esta apreciación de las variantes ha inspirado una interpretación de los textos centrada en la cultura manuscrita (manuscript culture) 9 . El manuscrito se analiza como artefacto. Se abandona el estudio del texto en abstracto, separado de su aspecto físico y de su presentación, porque se considera que la obra literaria no existe fuera de su encarnación material. En otras palabras, la condición física es parte del significado del texto, ya que la producción del artefacto está determinada por factores sociales, económicos e intelectuales tanto en su origen como en su uso. Más aún, estos condicionamientos son el camino para llegar a las personas que produjeron, poseyeron y leyeron los manuscritos y descubrir sus contextos socio-históricos, culturales y religiosos. Consecuentemente, el análisis implica un distanciamiento de cuestiones tales como la autoría y la intención del autor y se fija más en la recepción, lectura y uso concreto de los manuscritos. Asimismo, privilegia al lector más que al autor y/o su texto y por ello se centra sobre todo en la historia de la transmisión, en donde el estudio de los textos en sus contextos-manuscritos puede revelar "un proceso de crear un sentido de muchas capas que es a menudo discutido" $"$.

El resultado de este tipo de aproximación queda reflejado en cómo los estudios sobre las prácticas de los escribas, la producción de manuscritos, la copia, circulación y transmisión de los textos, la alfabetización, la lectura y memorización, la oralidad y auralidad, y otros contextos relacionados con el uso de textos antiguos han proliferado en los últimos años. Mediante estos estudios, el paradigma histórico-crítico no solo ha sido revisado sino que se ha profundizado también en el modo en que los textos interactúan con sus lectores o público en general ${ }^{11}$.

9 Liv Ingeborg Lied - H. Lundhaug, "Studying Snapshots: On Manuscript Culture, Textual Fluidity, and New Philology", en ID. (eds.), Snapshots of Evolving Traditions. Jewish and Christian Manuscript Culture, Textual Fluidity, and New Philology (De Gruyter, Berlin-New York 2017) 1-19. Los párrafos que siguen están basados en buena medida en este artículo.

10 M. P. Penn, "Monks, Manuscripts, and Muslims: Syriac Textual Changes in Reaction to the Rise of Islam”, en Hugoye 12 (2009) 235-257, aquí 251 (citado por L. I. LiED H. Lundhaug, "Studying Snapshots...", 8).

11 L. I. Lied - H. Lundhaug, "Studying Snapshots...", 2. 
Este modo de acercarse a las variantes explica también el interés de la Nueva Filología en la fluidez textual. En una cultura manuscrita es evidente que los textos cambian -intencionada y accidentalmentecuando se copian. Se produce un proceso en el que el texto se desarrolla a la vez que se transmite. La consecuencia es lo que John Bryant llama fluid text, refiriéndose también con ello a toda obra literaria que existe en una variedad de versiones (desde los borradores del autor hasta las pruebas de imprenta, ediciones revisadas, adaptaciones para el cine, etc.). Según Bryant, todas estas versiones deben ser tenidas en cuenta en sus contextos culturales porque ofrecen un registro valioso de la interacción entre el artista y la sociedad. La razón -opina el profesor americano- es que las obras literarias no son productos inamovibles, sino obras en progreso, que fluyen, se mueven y cambian según su situación cultural ${ }^{12}$.

Como se puede observar, los desarrollos brevemente enunciados prescinden de la preocupación por un texto estable y rechazan la comprensión de la variante como corrupción textual. En cambio, consideran que los cambios que se introducen en el proceso de transmisión son aspectos importantes de la vida del texto, tal como quedan testimoniados en los manuscritos individuales, como instantáneas (snapshots) de ese texto. Estudiar los textos en su fluidez muestra que las tradiciones textuales nunca son lineales sino que en el proceso de copiarse a veces se rompen, se interrumpen o se trasforman profundamente. El resultado de esta visión lleva a considerar la crítica textual ya no como el estudio de los testimonios de un texto anterior, sino como la ciencia que debe preguntarse hasta qué punto esos textos con sus variantes reflejan los intereses y preocupaciones de los que los produjeron y poseyeron, en qué medida se puede llegar al texto "original" y qué grado de "fluidez" se puede esperar en relación al texto o textos examinados ${ }^{13}$.

12 Este es el motivo por el que a Bryant le interesa estudiar cómo fluye y cambia el texto en el proceso de ser copiado y revisado. Ver J. L. BRyant, The Fluid Text. A Theory of Revision and Editing for Book and Screen (Ann Arbor, The University of Michigan Press 2002).

13 L. I. Lied - H. Lundhaug, "Studying Snapshots...", 9. 


\section{Filología material neotestamentaria}

Se debe señalar que estas nuevas tendencias de la crítica textual que surgen en ámbito de la filología medieval no son exclusivas de este campo. Bastantes años antes, en el marco del estudio de la transmisión del texto y del análisis de los manuscritos del Nuevo Testamento, se había ido desarrollando una preocupación paralela, análoga en muchos aspectos a la que presenta la Nueva Filología. Se trataba de un modo de hacer crítica textual que más o menos simultáneamente y por vías diversas llega a confluir con las propuestas de los críticos textuales medievalistas.

Un precedente importante de este nuevo enfoque es la obra que en 1966 Eldon Epp publica sobre las tendencias teológicas del códice de Beza en Hechos de los Apóstoles. En ella el profesor de Harvard estudia cómo las opiniones antijudías de la época en que se copia el manuscrito se ven reflejadas en las variantes textuales de ese códice ${ }^{14}$. Casi tres décadas después, Bart Ehrman publica una obra sobre lo que él denomina "corrupción ortodoxa" de la Escritura y que se va a convertir en paradigmática del modo en que algunos autores empiezan a entender la crítica textual del Nuevo Testamento ${ }^{15}$. En consonancia con la Nueva Filología, pero por caminos independientes, Ehrman subraya cómo muchas de las variantes textuales neotestamentarias han surgido con el fin de evitar interpretaciones que los escribas consideraban heréticas (sobre todo, adopcionistas, separacionistas, docetas y patripasianas) y que les llevaba a "corromper" los textos para defender un cristianismo ortodoxo (frente a judíos, paganos y herejes) y para mantener una particular visión de la mujer ${ }^{16}$.

14 E. J. Epp, The Theological Tendency of Codex Bezae Cantabrigiensis in Acts (Cambridge University Press, Cambridge 1966).

15 B. D. Ehrman, The Orthodox Corruption of Scripture: The Effect of Early Christological Controversies on the Text of the New Testament (Oxford University Press, Oxford - New York 1993).

16 W. C. Kannaday, Apologetic Discourse and the Scribal Tradition: Evidence of the Influence of Apologetic Interests on the Text of the Canonical Gospels (Society of Biblical Literature, Atlanta 2004), sigue una línea semejante a la de Ehrman, argumentando que las necesidades apologéticas de los siglos II y III influenciaron la transmisión del texto de los Evangelios. 
Sin embargo, quien se muestra quizá más en conformidad con las propuestas de la Nueva Filología -y, por lo que sé, también por caminos diferentes- es David Parker en su obra The Living Text of the Gospels ${ }^{17}$. Aunque volveré sobre ella más abajo, se puede afirmar que el libro de Parker concuerda con los aspectos subrayados por la Nueva Filología, especialmente en lo que se refiere a la fluidez textual y a la atención que presta a la materialidad de los manuscritos existentes, prescindiendo de la búsqueda del texto original. El profesor británico sostiene que la crítica textual debe tener como objeto de estudio los manuscritos en su variedad, tal como nos han llegado, y que la fluidez textual materializada en la pluralidad de textos que conservamos muestra que la noción de un único texto autoritativo es ajena a la tradición de los orígenes. Sostiene que, como el texto impreso corre el peligro de ser interpretado como el texto normativo (cuando nunca existió en esa forma en ningún manuscrito), la interpretación de los textos debe versar sobre lo que los manuscritos concretos quieren transmitir y no sobre ese hipotético texto original (y por ende normativo).

Simultáneamente, en torno a estos mismos años, el interés por la manuscript culture de la que hablaban los medievalistas se ha hecho también presente en el campo del Nuevo Testamento. Reflejo de ello son los estudios de Gamble, Haines-Eitzen, o Hurtado ${ }^{18}$, y las publicaciones sobre las tendencias que tienen los escribas al introducir diversos tipos de cambios en los manuscritos que copian. En este sentido, es antológica la obra de James Royse, que analiza minuciosamente esos hábitos en los seis papiros más antiguos y más extensos del Nuevo Testamento que

17 D. C. PARKer, The Living Text of the Gospels (Cambridge University Press, Cambridge 1997). Sobre esta obra se celebró el 2017 un congreso en Birmingham con ocasión de los 20 años de su publicación.

18 La obra de H. Y. GAmble, Books and Readers in Early Christianity (Yale University Press, New Haven 1997), versa sobre la producción, circulación y uso de libros y sobre sus lectores en la Iglesia de los primeros siglos. Por su parte, KIM HaINes-EitZen, Guardians of Letters: Literacy, Power, and the Transmitters of Early Christian Literature (Oxford University Press, New York 2000), estudia quiénes eran los escribas que copiaron la literatura cristiana en los siglos segundo y tercero, y qué papel desempeñaron en la copia, transmisión e interpretación de esos textos. L. HuRTADO, The Earliest Christian Artifacts: Manuscripts and Christian Origins (Eerdmans, Grand Rapids, 2006), se ocupa de los primitivos códices cristianos, en cuanto objetos materiales que revelan una cultura específicamente cristiana mediante el formato, los nomina sacra o el estaurograma. 
conservamos $^{19}$. Una buena síntesis de este modo nuevo de aproximarse a los manuscritos es el artículo de Ehrman titulado "The Text as Window", en el que repasa algunos estudios que se han realizado sobre la historia de la transmisión de los textos del Nuevo Testamento como modos de entrar en el mundo social de los primeros siglos del cristianismo. El profesor americano sostiene que el análisis de los cambios que los escribas introdujeron al copiar los textos permite reconstruir el contexto sociohistórico de los escribas que reflejan esos cambios, de tal modo que "las variantes ya no son pura paja que se debe descartar según el modelo del texto original [...] sino pruebas valiosas para la historia del movimiento cristiano primitivo"

Finalmente, se debe añadir que estas aproximaciones son inseparables de la historia de la recepción de los textos manuscritos en el contexto de la Wirkungsgeschichte ${ }^{21}$.

19 J. R. Royse, Scribal Habits in Early Greek New Testament Papyri (NTTSD 36; Brill, Leiden 2007). En la misma línea se encuentra el estudio de J. Hernández Jr., Scribal Habits and Theological Influences in the Apocalypse. The Singular Readings of Sinaiticus, Alexandrinus, and Ephraemi (Mohr Siebecek, Tübingen 2006), sobre las prácticas de los escribas y las influencias teológicas que revelan las lecturas singulares de los códices de los siglos cuarto y quinto. Casi simultáneo a este, se publicó el estudio de D. Jongkind, Scribal Habits of Codex Sinaiticus (Gorgias Press, Piscataway, NJ 2007), sobre esos mismos hábitos presentes en el Códice Sinaítico. En el mismo ámbito, más recientemente ha aparecido la obra de P. MaLIK, P.Beatty III (P47): The Codex, its Scribe, and its Text (NTTSD 52; Brill, Leiden 2017) sobre el códice en papiro P47, la copia extensa más antigua que conservamos del Apocalipsis.

20 B. D. Ehrman, "The Text as Window: New Testament Manuscripts and the Social History of Early Christianity", en B. D. Ehrman - M. W. Holmes (eds.), The Text of the New Testament in Contemporary Research: Essays on the Status Quaestionis, Second Edition (NTTSD 42; Brill, Leiden 2012) 803-830, aquí 804.

21 La producción, transmisión e interpretación de un texto son vistos como elementos que entretejen la historia de su recepción, analizando en definitiva lo que ese texto parece y lo que puede obrar. Cf. B. W. Breed, Nomadic Text: A Theory of Biblical Reception History (Indiana University Press, Bloomington - Indianapolis 2014). Ver también ID., "What Can a Text Do? Reception History as an Ethology of the Biblical Text", en Emma England - W. J. Lyons (eds.), Reception History and Biblical Studies. Theory and Practice (Bloomsbury T\&T Clark, London - New York 2015) 95-109. 


\section{Tradición material y "traducción viva"}

Ciertamente, los primeros manuscritos del texto griego del Nuevo Testamento que han llegado hasta nosotros son el resultado de una tradición manuscrita que no estaba sujeta al rigor de transmisión que se da en épocas posteriores. De hecho, no se debe olvidar que no tenemos un manuscrito idéntico a otro. Como se ha dicho, Parker, en la obra citada más arriba, se fija en esta variedad para proponer una crítica textual realizada de un modo diverso del tradicional. Para ello se apoya en buena medida en el carácter libre que tiene el texto del códice de $\mathrm{Beza}^{22}$, argumentando que este manuscrito refleja la actitud más original que adoptaban los cristianos de las primeras generaciones a la hora de transmitir las palabras de Jesús. Dicho de otro modo, la diversidad textual que observamos en los manuscritos sería señal de que al principio las palabras de Jesús se trasmitían libremente. Sentada esta premisa, subraya la relación entre texto escrito y tradición oral: "La tradición vive como tradición escrita que ha sobrevivido y como tradición que hemos recibido. Los manuscritos que conservamos y la palabra hablada no son simples portadores de una tradición viva anterior. Son la tradición viva" ${ }^{23}$. Por eso -afirma- la búsqueda de un único texto autoritativo es una distorsión de la tradición, porque el concepto de texto autoritativo que se utiliza ampliamente en la actualidad es ajeno a esa tradición. Y se pregunta si el hecho de que el texto fuera en los inicios notablemente libre no preserva el espíritu del uso primitivo de las palabras de Jesús, "precisamente porque la letra ha sido alterada" ${ }^{\prime 24}$.

Sin duda, esta y otras afirmaciones de su libro son discutibles ${ }^{25}$. Quizá lo más difícil de aceptar es su comprensión del grado de libertad con que actuaban los copistas, pues, si bien seguramente había cierta flexibilidad a

22 D. C. Parker, Codex Bezae. An Early Christian Manuscript and its Text (Cambridge University Press, Cambridge 1992) 261-286, defiende que fue copiado en Berytus (actual Beirut) en el siglo $\mathrm{V}$, aunque su texto se remonta al siglo II.

23 D. C. Parker, The Living Text..., 210.

24 D. C. Parker, The Living Text..., 202.

25 De hecho, no son pocas las críticas que ha recibido, si bien quienes las han realizado admiten la honestidad y rigor de su análisis. Ver, por ejemplo, la larga recensión de M. Silva en Westminster Theological Journal 62 (2000) 295-302 o la de P. J. Williams en TC: A Journal of Biblical Textual Criticism (2013) (<http://rosetta.reltech.org/TC/v18/ TC-2013-Rev-Parker-Williams.pdf $>$ consultado 5.7.2018). 
la hora de transmitir oralmente las palabras de Jesús, no tenemos pruebas suficientes para afirmar que - una vez esas palabras hubieran sido puestas por escrito- los escribas las alteraran indiscriminadamente. Es decir, mientras no se demuestre lo contrario, no hay pruebas suficientes para negar que los copistas trataban de reproducir un texto, aunque en ocasiones se concedieran alguna libertad y lo alteraran, de manera accidental las más de las veces, en otras -las menos- conscientemente. Si al principio el texto hubiera sido "libre" deberíamos tener más testimonios de esa libertad y no la uniformidad (a pesar de las variantes) que vemos en los manuscritos que conservamos. Lógicamente, el problema es definir qué se entiende por libertad o fluidez y qué se entiende también por texto autoritativo. Siendo heredero de la tradición reformada, se comprende que Parker tenga dificultades para compaginar la tradición manuscrita tal como nos ha llegado y la idea de un texto original intocable, convertido prácticamente en referente último de la fe, separado en buena medida de la tradición ${ }^{26}$. De ahí que sus llamadas a la necesidad de entender el texto como parte de la tradición sean oportunas y su análisis sirva como una llamada de atención ante el peligro de querer establecer un texto autoritativo incuestionable desde el punto de vista literal.

Aun así, la existencia de un texto inicial libre debe ser matizada. No todas las variantes tienen el mismo peso, ni todas ellas, por ejemplo, permiten convertir el texto en un texto con categoría de "versión". Las versiones larga y corta del libro de Tobías, por ejemplo, son una cosa; y los errores de los escribas y las alteraciones intencionales de estos, otra. Por ello, el concepto de "fluidez" es demasiado ambiguo para expresar el modo en que se copiaban los textos. No obstante, esto no significa negar una variedad textual que en algunos casos permita reconocer el Sitz im Leben de los escribas, ni que determinadas variantes puedan

26 No obstante, sus presupuestos son, en última instancia, los propios de la teología reformada. Así lo sugiere el siguiente texto de D. C. PArker, The Living Text..., 211: "[T] he heart of the matter is that the definitive text is not essential to Christianity, because the presence of the Spirit is not limited to the inspiration of the written word [...] a belief in single authoritative texts accords to the Spirit a large role in the formation of Scripture, and almost none at all in the growth of the tradition. Once the distinction has been abolished in the way that we have attempted above, it is possible fully to acknowledge that the very life and whole life of the church is in the Spirit". 
reflejar preocupaciones doctrinales o deseos de ofrecer un texto mejor. La variación textual, ciertamente, es una manifestación del carácter vivo del texto.

Pues bien, en el marco de esta comprensión del texto como texto vivo encajan también las versiones antiguas a otras lenguas. Las primeras traducciones de los textos bíblicos, y en concreto del Nuevo Testamento, son valiosas porque no solo testimonian el texto del que derivan, sino porque también reflejan una tradición viva y permiten estudiar aspectos del mundo social en que surgieron. En otras palabras, así como las versiones del Nuevo Testamento tienen valor, entre otras cosas, porque sirven para recuperar parte del texto griego que utilizó el traductor o porque pueden transmitir información geográfica sobre los lugares donde circuló el texto (Siria, Egipto, etc.), las traducciones antiguas también pueden ofrecer indicios del modo en que un determinado pasaje fue entendido en un tiempo y lugar concretos, a partir del lenguaje y la interpretación particular que se hace de ese texto ${ }^{27}$.

El análisis de las páginas que siguen quiere ilustrar estas afirmaciones, prestando atención solamente a las traducciones latinas, por cuanto ocupan un lugar destacado entre las versiones del Nuevo Testamento. Ciertamente, como otras traducciones, las latinas presentan problemas de orden metodológico a la hora de establecer el valor del texto griego subyacente, puesto que los diversos textos de la Vetus Latina y la Vulgata están entremezclados y necesitan ser desenmarañados ${ }^{28}$. Por otra parte, el lenguaje de la Vetus Latina tiene la dificultad añadida de ser poco pulido y no presenta una forma unitaria de texto, como lo reconoce el mismo Jerónimo cuando el Papa Dámaso le pidió preparar la revisión de esos textos que acabó en la Vulgata de 383 y, todavía hoy se discute el origen

27 D. C. Parker, An Introduction to the New Testament Manuscripts and their Texts (Cambridge University Press, Cambridge 2008) 118-119; ID., The Living Text..., 14.

28 El vasto número de manuscritos de estas versiones que se han conservado, en concreto más de 10.000, de los que 50 (datados entre los siglos cuarto y trece) son representantes de la Vetus Latina, lo hace necesario. Cf. D. C. PArker, The Living Text..., 14. 
de la Vetus Latina y si nació en el norte de África a finales del siglo II o en otros lugares ${ }^{29}$.

A pesar de estas limitaciones, las versiones latinas tienen mucho que contar. A medida que el texto traducido al latín era copiado se introducen en él cambios que en ocasiones obedecen a la historia de la propia versión y a las exigencias propias de la lengua en que se vierte el texto, y que resultan útiles para mostrar el carácter vivo que tiene ese texto. En este sentido, son particularmente iluminadoras aquellas variantes que parecen haber sido realizadas de manera intencional, sobre todo si dejan traslucir las razones que motivaron esos cambios. Hay que advertir, sin embargo, que es muy difícil determinar esta intencionalidad y, dada la variedad de causas posibles, cada caso debe ser analizado individualmente.

\section{1. ¿Lecturas originales?}

Hay pasajes en los que el texto de la traducción parece reflejar una lectura más cercana al original que la testimoniada por el texto griego, de donde parece haber desaparecido por motivos doctrinales, que la versión latina ha tenido en cuenta cuando se copió el manuscrito. Ilustraré la cuestión con dos ejemplos del cuarto Evangelio ${ }^{30}$.

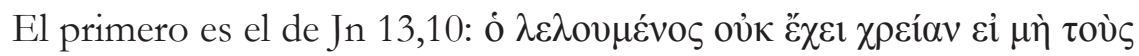

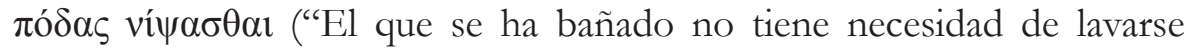
más que los pies"). En este lugar, tres manuscritos de la Vetus Latina (Colbertinus (c (6)), el Würzburg Universität M. P. Th. F. 67 (11A) y el Fragmentum Milanense ( $\rho(24)$ ) añaden el adverbio semel ("una vez") que no tiene su equivalente en manuscritos griegos, y traducen el texto griego por: qui lotus est semel non indiget nisi ut pedes lavet ("el que se ha bañado una vez no necesita más que lavarse los pies") ${ }^{31}$. Surge entonces la pregunta si

29 Ver J. Petzer, "The Latin Version of the New Testament”, en B. D. Ehrman - M. W. Holmes (eds.), The Text of the New Testament..., 113-130.

30 Para una panorámica de los manuscritos de la Vetus Latina del cuarto Evangelio, H. A. G. Houghton, The Latin New Testament: A Guide to Its Early History, Texts, and Manuscripts (Oxford University Press, Oxford 2008) 165-167. Una trascripción completa de los manuscritos de la Vetus Latina de Juan se encuentra en <http:// www.iohannes.com/vetuslatina> (consultado 5.7.2018).

31 El Sangermanensis primus ( $\left.g^{1}(7)\right)$, y algunos manuscritos de la Vulgata cambian el orden de palabras y leen qui semel lotus est. 
el texto latino refleja una variante griega perdida, o si la presencia de semel es una forma de indicar el carácter que tiene el tiempo perfecto griego (como modo de expresar algo definitivo que se hace una vez para siempre), o si el adverbio fue introducido en el contexto de una controversia teológica sobre la repetición del bautismo ${ }^{32}$, algo que podría venir avalado por varias obras de Agustín y Ambrosio que presentan semel junto a las palabras qui lotus est ("el que se ha bañado") para traducir el participio griego $\lambda \varepsilon \lambda o v \mu \varepsilon ́ v o \varsigma$, como en los manuscritos arriba mencionados ${ }^{33} \cdot$ ¿Cuál de las tres posibilidades ha de preferirse? La respuesta no es fácil. Que sea una manera de traducir el perfecto griego, indicando que la acción se ha realizado de forma definitiva, no parece probable, aunque no es fácil de demostrar. Que obedezca a controversias sobre la repetición de bautismo es también difícil de determinar y, en cualquier caso, resulta poco plausible. Al menos, no parece que las ocurrencias en las obras de san Agustín obedezcan a que el obispo de Hipona haya introducido por su cuenta este adverbio porque le fuera propicio para la polémica contra los donatistas, sino que es más probable que lo hubiera encontrado ya en la tradición ${ }^{34}$. De hecho Tertuliano (De baptismo 12.3) y Optato (Contra Donatistas 4.4 y 5.3) también leen semel en este versículo (incluso Jerónimo lee en Aduersus Ioninianum 2.3: qui lotus est non necesse habet uti iterum lauet ["el que se ha bañado no tiene necesidad de lavarse de nuevo"]). ${ }^{35}$ Por tanto, quizá haya que pensar que los manuscritos de la Vetus Latina que leen semel están trasmitiendo un texto original que, sin embargo, no ha dejado huella en la tradición manuscrita griega. La cuestión, no obstante,

32 Cf. P. Burton, “The Latin Version of the New Testament", en B. D. Ehrman - M. W. Holmes (eds.), The Text of the New Testament in Contemporary Research..., 167-200, aquí 195. H. A. G. Houghton, The Latin New Testament..., 166.

33 H. A. G. Houghton, Augustine's Text of John. Patristic Citations and Latin Gospel Manuscripts (Oxford University Press, Oxford 2008) 303-304; W. L. Petersen, Tatian's Diatessaron. Its Creation, Dissemination, Significance and History in Scholarship (Brill, Leiden 1994) 380-384.

34 H. A. G. Houghton, Augustine's Text of John..., 75 y 305.

35 Para los testimonios de los Padres al respecto ver M.-F. BERrouard, Cuvres de saint Augustin. Homélies sur l’Evangile de saint Jean LV-LXXIX. Traduction, introduction et notes (Bibliothèque Augustienne, 74a; Institut des Études Augustiniennes, Paris 1993) 404. 
permanece abierta ${ }^{36}$. En cualquier caso, es una muestra de la dificultad que entraña determinar la lectura más original y revela hasta qué punto el texto que se recibe puede ir enriqueciéndose en su trasmisión sin que necesariamente haga traición al texto recibido.

El otro ejemplo es el de Jn 7,1. La mayoría de los manuscritos griegos

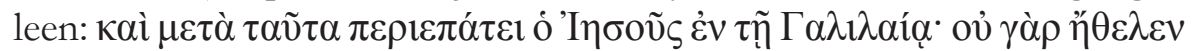

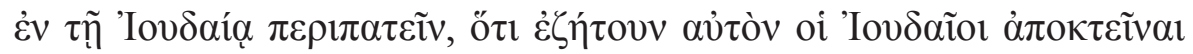
("Después de esto andaba Jesús por Galilea, pues no quería andar por Judea, ya que los judíos le buscaban para matarle"). En cambio, el códice Freer de Washington (W) y dos minúsculos (196 y 743) presentan la

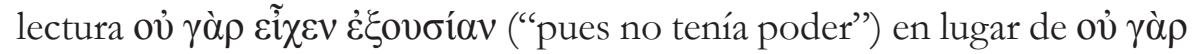
$\ddot{\eta} \theta \varepsilon \lambda \varepsilon v$ ("pues no quería"). Siendo una lectura tan minoritaria en griego, sorprende que, sin embargo, esté testimoniada por cinco manuscritos de la Vetus Latina, incluyendo los más antiguos: a (3), b (4), ff ${ }^{2}(8), 1$ (11), $\mathrm{r}^{1}$ (14). Estos leen: non habebat potestatem ("no tenía poder"). La lectura está también apoyada por la versión siriaca curetoniana y, como veremos, un comentario de Juan Crisóstomo en su Homilía 48 sobre el Evangelio de $\mathrm{Juan}^{37} \cdot$ ¿Es posible que fuera esta la lectura original? Dado que la expresión

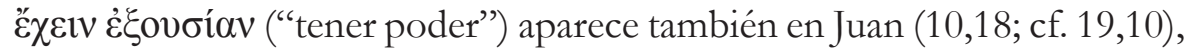
que el uso de É $\chi \varepsilon ı v$ seguido de un sustantivo es característico del estilo del evangelista (cf. 3,16; 4,44; 9,41), que $\dot{\varepsilon} \xi$ ov бía es un concepto importante en este evangelio y dado sobre todo que se trataría de la lectio difficilior ("no quería" es, en principio, más suave que "no tenía poder"), parece

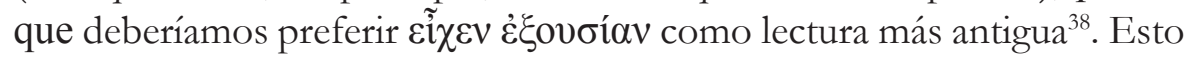
vendría confirmado por un testimonio del Crisóstomo, donde se observa que tenía a su disposición un texto griego con esa lectura y, conforme al modo en que cita ese texto, parece sugerir que era habitual que el pasaje

36 De todas formas, se debe añadir que el códice Colbertinus, aunque importante, es el último de los testigos de la Vetus Latina que tenemos de Juan y el fragmento de Milán, aunque datan del siglo VII o VIII vienen de un leccionario galicano, por lo que su testimonio no es particularmente fuerte. Ver H. A. G. Houghton, Augustine's Text of John ..., 75.

37 En cambio los manuscritos latinos aur, c, d, e, f, q y Vg (apoyada por la versión siriaca sinaítica) leen non volebat (e: non habebat uoluntatem).

38 Sin embargo, para P. BurTon, “The Latin Version of the New Testament...”, 192, estas razones no son suficientes para confirmarlo. Indica que un buen imitador podría haber creado fácilmente una expresión de estilo joánico. Cf. También H. A. G. Houghton, The Latin New Testament..., 166. 
se entendiera como "no tener autoridad". De hecho, se sorprende por la presencia de esta expresión, en la medida que implicaba cuestionar el poder de $\mathrm{Cristo}^{39}$, lo que vendría a confirmar que se trataba de la lectura más difícil y por tanto la que deberíamos preferir ${ }^{40}$.

Sin embargo, los argumentos no son definitivos. De hecho, Riesner aboga por la lectura mayoritaria ("no quería") como lectio difficilior, ya que, en su opinión, "no querer ir a Judea” podía dar a entender que Jesús tenía miedo de que le mataran, mostrando así una debilidad incompatible con su condición. Para el estudioso alemán la lectura minoritaria - "no tenía poder" - no era la original sino que se explicaría como una armonización del texto que se dio en el siglo $\mathrm{II}^{41}$. En todo caso, a pesar de que esta lectura minoritaria cuenta con el apoyo de la Vetus Latina y que para muchos podría ser la más cercana al texto original, las ediciones críticas modernas mantienen la lectura mayoritaria. Metzger en su comentario textual señala que el comité para la edición crítica del texto griego del Nuevo Testamento se mostraba demasiado parcial para tomar una decisión a partir de un solo testigo externo (el códice Freer) y prefirieron dejar la lectura mayoritaria ${ }^{42}$.

39 JuAn Crisóstomo, In Ioannem, PG 59:269. El Crisóstomo se pregunta sorprendido cómo puede decir el evangelista que Jesús no tenía poder y luego aparecer en el templo, dejando que sus oyentes se sorprendan de que, siendo buscado para llevarlo a muerte, hablase sin problemas. El obispo responde diciendo que el evangelista se re-

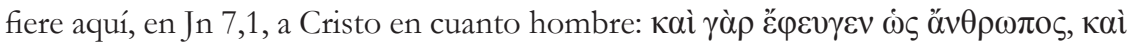

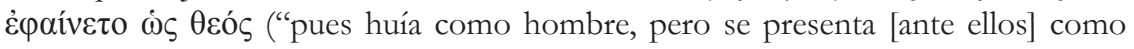
Dios"). Ver también R. Perşa, "Autenticitatea textului scripturistic in 7,1 în comentariul hrisostomic la evanghelia după Ioan”, en StTeo 13 (2014) 153-178.

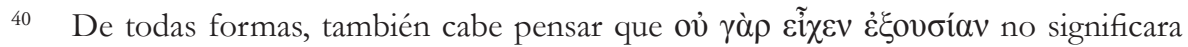
aquí "no tener autoridad o derecho" (lo que no tiene sentido a la luz de lo que sigue), sino simplemente "no ser capaz de" (W. Willker, A Textual Commentary on the Greek Gospels, Vol. 4: John (Bremen: Online published, 2015) ad. loc. <http:// www.willker.de/wie/TCG/TC-John.pdf> (consultado el 5.7.2018), y esta lectura pudiera admitirse como más antigua, sin tener que revisar necesariamente la teología de la autoridad de Jesús en el cuarto Evangelio. Así lo plantea P. Burton, "The Latin Version of the New Testament...", 192, en el caso de que la variante minoritaria sea la más antigua.

41 R. RIESNER, "Joh 7,1: fehlender Wille oder fehlende Vollmacht Jesu?", en ZNW 96 (2005) 259-262.

42 B. M. Metzger, A Textual Commentary on the Greek New Testament (Deutsche Bibelgesellschaft, Stuttgart ${ }^{2}$ 1994) 184-185 (ed. 1971, 215-216). 
Como se puede observar, no es fácilllegara una conclusión. No obstante, el pasaje escogido solo quiere mostrar cómo algunas traducciones latinas trasmiten un texto que difiere de la lectura mayoritaria, manifestando así el carácter vivo del texto original.

\subsection{Traducciones latinas modernas}

Hasta el momento, los ejemplos están tomados de las versiones antiguas. Sin embargo, la "fluidez" textual continúa de alguna forma en la traducción latina contemporánea, tal como se expresa en la Neovulgata. Lo ilustraré con otros dos ejemplos del cuarto Evangelio.

\subsubsection{Jn 8,25: principium quia et loquor vobis}

El primero es la célebre crux interpretum de Jn 8,25, la contestación

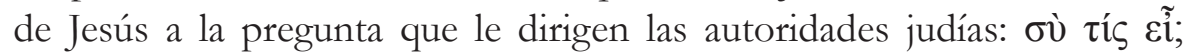
(“¿Tú quién eres?"). Como se sabe, el texto griego más frecuente en las

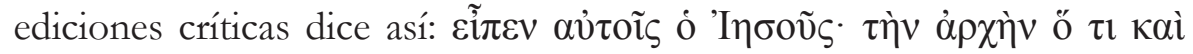
$\lambda \alpha \lambda \tilde{\omega} \dot{v} \mu \tilde{i} v^{43}$. ¿Pero cómo debe traducirse esta respuesta? Por un lado, ǒ $\tau$ se puede leer como ő $\tau$ ("porque") o como ö $\tau$ ("eso que") y puntuarse asimismo de diversas maneras. Consecuentemente, las palabras de Jesús

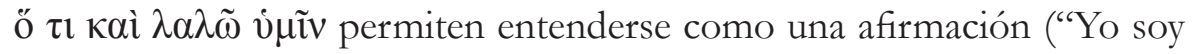
lo que os estoy diciendo"), una pregunta (“¿Qué es lo que os hablo?”),

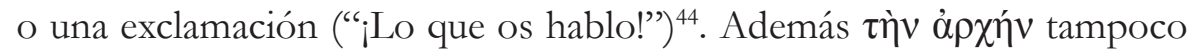
tiene un sentido claro. En la tradición oriental, algunos Padres y escritores eclesiásticos, aunque encuentran problemático el texto griego, lo resuelven

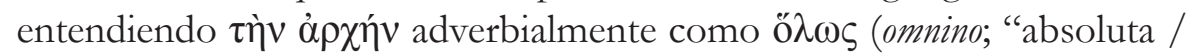

43 En la transmisión manuscrita el texto presenta algunas variantes. La lectura original del Sinaítico introduce $\tilde{\varepsilon} v$ ("una sola cosa") antes de $\lambda \alpha \lambda \tilde{\omega}$. Por su parte, el corrector

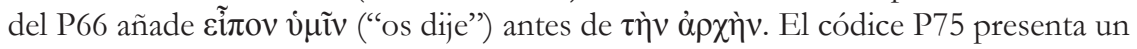
punto, después de la ómicron y debajo de la tau en ó $\tau$. Pero no está claro si es una

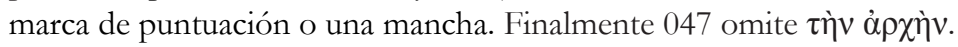

44 B. M. Metzger, A Textual Commentary..., 192-193 (ed. 1971, 223-224). 
fundamentalmente") o como $\dot{\varepsilon} \xi \hat{\alpha} \rho \chi \tilde{\eta} \varsigma$ ("desde el inicio / principio") ${ }^{45}$. Según se adopte una u otra interpretación, la respuesta del Maestro podría traducirse como: "Fundamentalmente, yo soy lo que os estoy diciendo", o "¿Qué es lo que os hablo en absoluto?”, o "iLo que os hablo absolutamente!", o "YYo soy] lo que os he dicho desde el principio". Los autores modernos disputan sobre cuál se debe preferir, aunque la indicada en último lugar ("[Yo soy] lo que os he dicho desde el principio"), quizá sea la mejor traducción.

Al menos es la opción de Nono de Panópolis y viene señalada también como posible por Cirilo de Alejandría ${ }^{46}$. De todas formas, resultan también atractivas la lectura del códice en papiro P66: عĩ $\varepsilon \varepsilon v$ $\alpha$ dijo: «Os dije al principio lo mismo que os estoy hablando [ahora]»" ${ }^{47}$ y la traducción propuesta recientemente por Förster, basándose en la puntuación del códice de Beza y del Basiliensis. Según esta puntuación,

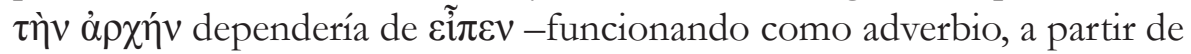
una construcción gramatical influida por el hebreo- y vendría a significar: "Jesús les dijo primero de todo/inmediatamente: Os estoy diciendo esto" (o bien "os estoy diciendo también esto") ${ }^{48}$.

45 Esta interpretación está en consonancia con una de las dos que ofrece Cirilo de Alejandría. Ver A. PIRAs, "Anastodeins, patei jah rodja du izwis. Gv 8,25 e la versione gotica della bibbia", en C. Falluomini - R. Rosselli Del Turco (eds.), Studi in onore di Vittoria Dolcetti Corazza (Edizioni dell'Orso, Alessandria 2015) 149-172, aqui 152-154. Entre otras cosas, el autor hace un recorrido de cómo se ha interpretado este texto. Ver también C. Rico, "Jn 8:25 au risque de la philologie: l'histoire d'une expression grecque", en RB 112 (2005) 596-627; ID. Le traducteur de Bethléem. Le génie interprétatif de saint Jérôme à l’aune de la linguistique (Cerf, Paris 2016) $137-$ 141.

46 Tras un estudio de la expresión en la literatura griega, C. Caragounis, "What did

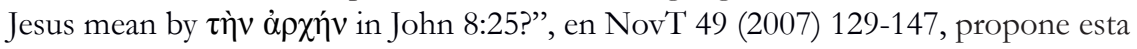
traducción: " $[\mathrm{I} \mathrm{am}]$ From the beginning! - precisely what I have been saying (speaking) to you". Y comenta: "The English may translate it with «[I am $]$ what I have been saying to you from the beginning», but this is only a functional reading deprived of the literary effect of the original".

47 R. E. Brown, El Evangelio segín Juan, vol. I (Cristiandad, Madrid 1999) 644.

48 H. FÖRSTER, "Grammatik von Joh 8,25 im Lichte der handschriftlichen Überlieferung", en ZNW 107 (2016) 1-29; ID., "Possible Similarities in the Linguistic Structure of John 8.25b and John 8.45a”, en Bible Translator 68 (2017) 164-178 (cf. 166-168). 
Hasta aquí el texto griego. Si nos fijamos ahora en las versiones latinas ${ }^{49}$, se observa que los traductores se encontraron con un texto difícil y optaron por una traducción servil ${ }^{50}$. La traducción de la Vetus Latina es bastante compacta y traduce el griego por: Dixit eis Iesus principium quod et loquor vobis; por su parte, la versión de la Vulgata lee: principium quia et loquor vobis. Se podrían traducir literalmente: "Jesús les dijo: «El principio que /

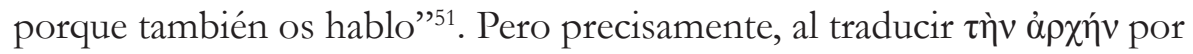
el nominativo/acusativo principium, que no tiene función sintáctica en latín, las versiones latinas dieron lugar a interpretaciones que van más allá de lo que permitía el texto griego. Así sucede en buena parte de la tradición occidental, que hace una exégesis anagógica de Cristo como principio ("YYo soy] el principio que también os hablo [o porque os hablo]"), algo

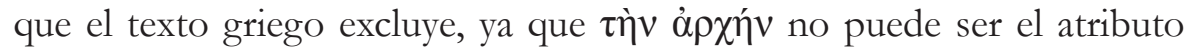
predicativo de un sobreentendido verbo $\varepsilon^{i} \mu i^{52}$.

Probablemente por esto, la traducción de la Neovulgata se aparta de esa tradición y prefiere leer: Dixit eis Iesus: In principio: id quod et loquor vobis! Tenemos aquí en consecuencia una corrección moderna de la traducción latina, realizada a partir del texto griego que hoy se considera mejor testimoniado, sin apoyo en las versiones latinas más antiguas. La puntuación que adopta la Neovulgata implica entender $\tau \grave{\eta} v \dot{\alpha} \rho \chi \eta ́ v$ como ö $\lambda \omega \varsigma$ (omnino) y, sobre la base del ö $\tau$, parece que quiere significar: "¡Ante todo / Al inicio, es lo que os estoy diciendo!”. La traducción es legítima, aunque más libre que la de la Vetus Latina y Vulgata, en cuanto que in principio correspondería a un supuesto $\dot{\varepsilon} v \dot{\alpha} \rho \chi \tilde{\eta}$, en lugar de al acusativo

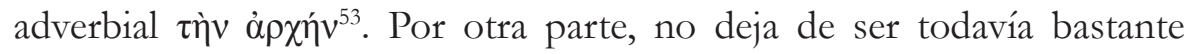

49 Las versiones antiguas no latinas tampoco ayudan mucho. Las versiones siriacas ignoran el sentido de omnino y subrayan el de "comienzo" (C. Rico, Le traducteur de Betbléem..., 140, n. 1); la versión bohaírica: "Al principio yo también os dije..." y la sahídica: "Desde el principio yo os hablo". El Diatéssaron Árabe traduce por "Si yo debiera hablaros a vosotros...". Ver W. WiLlker, A Textual Commentary..., ad loc.

50 A. Piras, “Anastodeins, patei jah rodja du izwis...”, 157.

51 Las variantes más relevantes son initium por principium en a (3) (Vercellensis) y c (6) (Colbertinus) e imprimis en b (4) (Veronensis), y quia en b (4), quoniam en d (5) (Beza) y qui en e (2) (Palatino). La ed. Clementina de la Vulgata: principium quod et loquor vobis. Cf. también H. A. G. Houghton, Augustine's Text..., 264.

52 A. PIRAs, “Anastodeins, patei jah rodja du izwis...”, 158-165.

53 C. Rico, Le traducteur de Betbléem..., 140-141. 
oscura y permite, para bien (fidelidad al texto griego) y para mal (al cerrar el paso a interpretaciones alegóricas), menos libertades que las que ofrece principium.

\subsubsection{Jn 20,17: noli me tangere}

Tomemos ahora otro pasaje que sirva de ejemplo de cómo las versiones antiguas afectan al modo de entender el texto griego mejor testimoniado. Es el caso de las célebres palabras de Jesús resucitado a María Magdalena

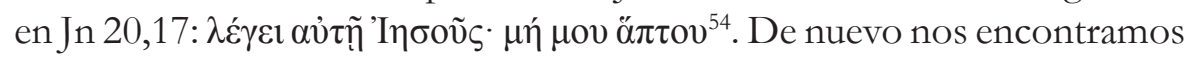
con un problema de traducción. ¿Debemos entender: "Le dice Jesús: no me toques", o, como aparece en muchas ediciones modernas del Nuevo Testamento, "Le dice Jesús: deja de agarrarme / suéltame"? Las versiones latinas testimoniadas tanto por la Vetus latina como por la Vulgata lo tradujeron sin variante alguna como: Dicit ei Iesus: noli me tangere ("Le dice Jesús: no me toques"). No obstante, los revisores de la Neovulgata parece que consideraron deficiente esta traducción latina al entender, conforme a la interpretación mayoritaria contemporánea, que la negación $\mu \eta ́$ seguida del imperativo de presente se emplea para detener una acción ya comenzada. En consecuencia, teniendo en cuenta que, según el griego

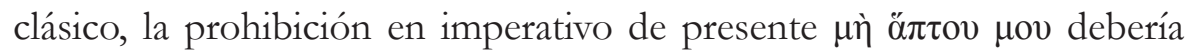
significar "deja de agarrarme" en lugar del aparente "no me toques" que sugiere el texto latino, los traductores de la Neovulgata corrigieron noli me tangere por iam noli tenere ("no me retengas / suéltame") una lectura aparentemente más acorde con el griego y con el aparente sentido del pasaje, pero no testimoniada en la tradición manuscrita latina.

La opción, de nuevo, es legítima. Ahora bien, ¿es enteramente satisfactoria? Por un lado, no se debe olvidar que en griego koiné la función del imperativo de presente no llevaba consigo necesariamente este sentido de continuidad que tenía el griego clásico. Junto al sentido tradicional, $\mu$ í seguido de imperativo de presente podía también indicar

54 Se trata de una lectura del texto griego, que no tiene variantes dignas de mención. Solo el códice Vaticano, cambiando el orden de las palabras, lee: $\mu$ ஸे ă $\pi \tau$ ov $\mu$ ov. 
la prohibición de iniciar un proceso ${ }^{55}$. Por tanto, desde el punto de vista del griego, cabría interpretarse que María Magdalena quiere tocar a Jesús y que éste le indica que no lo haga ${ }^{56}$. Es verdad que, exegéticamente, hay poderosas razones para considerar que aquí Juan utiliza el uso clásico, sobre todo si se compara la escena con la aparición de Tomás, en donde Jesús pide que le toque, y con las afirmaciones de Mt 28,9 ("Ellas se acercaron, abrazaron sus pies y le adoraron") y Lc 24,39 ("Mirad mis manos y mis pies: soy yo mismo. Palpadme y ved..."). Sin embargo, no se puede excluir, teóricamente, que el evangelista hubiera seguido un uso helenístico. De hecho, hay Padres y escritores eclesiásticos griegos, familiarizados por tanto con los usos de la lengua que dominaban, que lo entienden en este sentido. Ocurre, por ejemplo, con Orígenes ${ }^{57}$, Eusebio de Cesaréa ${ }^{58}$ y Cirilo de Alejandría ${ }^{59}$. Tampoco deja lugar a dudas el texto de Nono de Panópolis, quien siendo autor de una paráfrasis al Evangelio de Juan en 3.660 hexámetros dactílicos y autor también de las Dionisiacas,

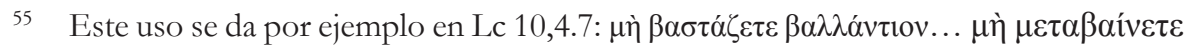

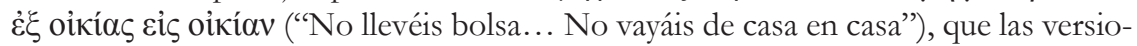
nes traducen por: Nolite portare sacculum... nolite transire de domo in domo. Ver también C. Rico, Le traducteur de Betbléem..., 149.

56 Cf. BDF $₫ 336.5$.

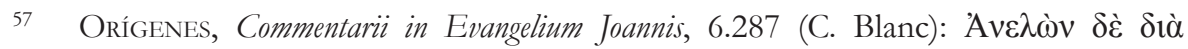

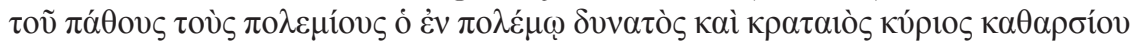

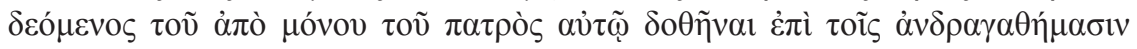

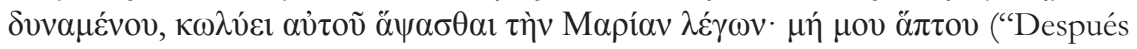
de que ha destruido a sus enemigos por su pasión, el Señor, que es poderoso y fuerte en la batalla, necesitando la purificación por sus obras humanas que le han sido dadas a él solo por su Padre, impide que María le toque diciendo: No me toques..."). También 6.291, 10.245 y 13.180.

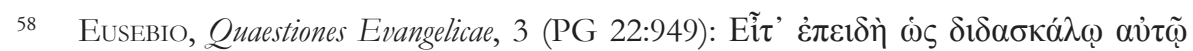

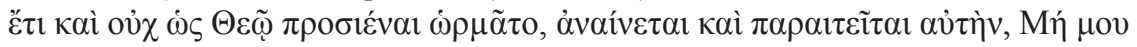
ă $\pi$ tov ("Como comenzaba a ir hacia él como se va hacia un maestro y no como conviene a Dios, [Jesús] la evita y la rechaza diciendo: No me toques)". Cf. C. Rico, Le traducteur de Betbléem..., 149-150.

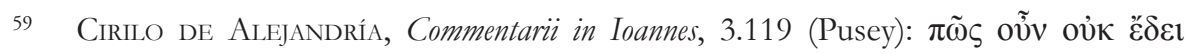

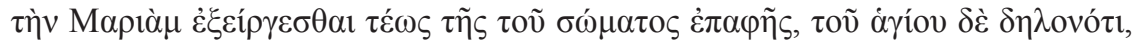

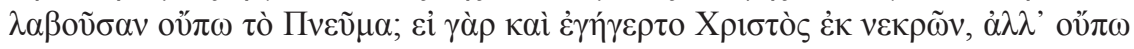

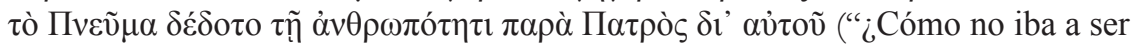
conveniente que a María se le impidiera tocar su cuerpo, que era claramente santo, si todavía ella no había recibido el Espíritu? Pues aunque Cristo había resucitado de los muertos, el Padre todavía no había dado el Espíritu por medio de él a la humanidad"). 
el último y más extenso gran poema de la Antigüedad clásica (21.286 versos, distribuidos en 48 libros, los mismos que suman la Ilíada y la Odisea), no parece probable que no conociera bien los diversos usos de la lengua griega. Y, sin embargo, el de Panópolis no vio reparo alguno en entender ese imperativo de presente como prohibición de iniciar una acción y parafraseó el texto de esta manera: "Y Dios frenó a la mujer que iba derecha a aproximarse hacia el vestido inmortal. Y le dijo una palabra: «No toques mis vestiduras, pues todavía no he regresado a mi Padre después de la muerte»". Ciertamente, las tendencias quasi-docetas de Nono podrían explicar en parte su traducción. Pero tampoco Juan Crisóstomo escapa a esta manera de entender el texto y se inclina por pensar que Jesús evita que María le toque porque esa acción no estaría conforme con su dignidad de resucitado ${ }^{60}$. Por tanto, a pesar de que la traducción que se ha impuesto en la actualidad interpreta que María estaría agarrando a Jesús, el problema no queda resuelto. De ahí que haya también quien elige una vía parecida a la clásica y considere más probable

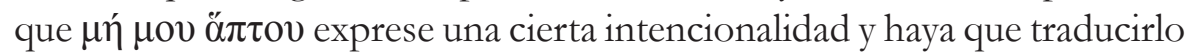
por: "No intentes tocarme" o "No te acerques", en conformidad con el

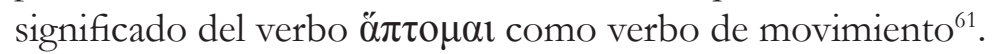

Dicho esto, tampoco está tan claro que la traducción latina de Noli me tangere implique necesariamente el sentido habitual de rechazo que a primera vista parece significar el texto y ha dado lugar a las representaciones pictóricas clásicas. De hecho, es interesante que los códices de la Vetus Latina Sangermanensis secundus, $g^{2}$ (29) y Sangallensis (48, aunque aquí tachado por el corrector) añaden un pequeño inciso: et occurrit ut

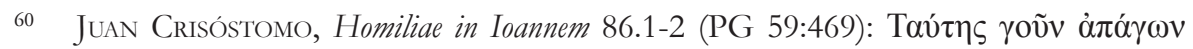

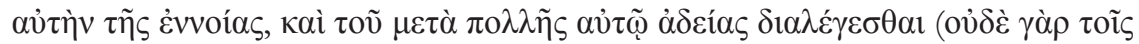

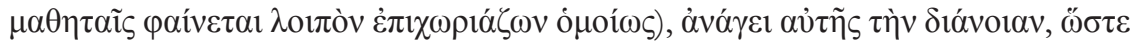

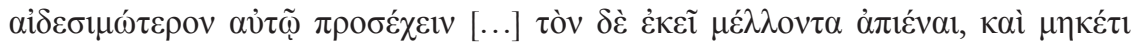

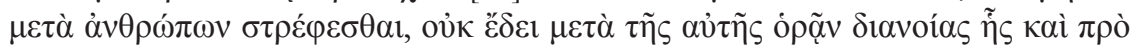

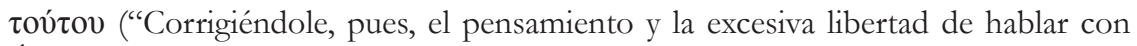
Él [pues vemos que ni con los discípulos se le ve que conversa así], la levanta en su modo de razonar a fin de que lo trate con más reverencia [...] A quien ha de subir allá y no estará ya más con los hombres, no convenía en adelante tratarlo del mismo modo que antes").

61 R. Bieringer, "Noli me tangere and the New testament: an exegetical approach", en Barbara Baert y otros (eds.), Noli me tangere. Mary magdalene: One Person, Many Images (Peeters, Leuven 2006) 13-28. 
tangeret eum Dicit ei Iesus noli me tangere ("y sucedió que como [María] le tocara, Jesús le dice: no me toques”). Es evidente, por tanto, que, para un latino, la prohibición no entraba en contradicción con detener una acción ya comenzada. Lo mismo parece sugerir Agustín, quien interpreta la orden de Jesús como una referencia mística a la divinidad de Cristo, que solo puede ser tocado por la fe, pero dando a entender que la expresión no excluía que María pudiera estar agarrándole ${ }^{62}$. Estos ejemplos muestran que en Occidente había quienes entendían que noli me tangere no implicaba una prohibición de iniciar una acción. Así lo confirmaría también el uso de nolo. Este verbo en imperativo no solo indica prohibición de no hacer algo, sino también orden de dejar de hacer algo ya iniciado. La traducción

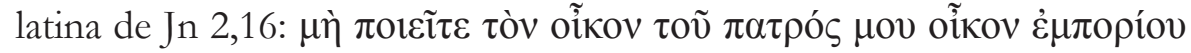
("no hagáis de la casa de mi Padre una casa de negocio") es: nolite facere domum patris mei domum negotiationis, que permite entenderse como "dejad de hacer de la casa de mi Padre un negocio...". Lo mismo sucede en Jn

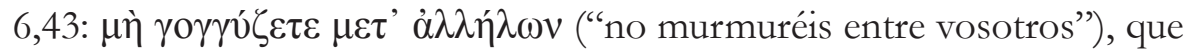
la Vetus Latina y la Vulgata traducen por: nolite murmurare invicem (o inter uos). La prohibición implica dejar de criticar, porque de hecho es lo que estaban haciendo. Así pues, como el latín no tiene la posibilidad de indicar el aspecto como el griego y dado el carácter literal de la traducción de la Vetus Latina y de la Vulgata, no es de extrañar que los imperativos de aoristo y de presente se traduzcan a veces de la misma manera. Por tanto, ni desde el punto de vista lingüístico ni desde el punto de vista exegético se excluye que el imperativo de presente señalado por Juan 20,17 pueda indicar en griego una prohibición de iniciar un proceso ni que en latín

62 Agustín, Sermo 245.2.2: Quid ergo est: Noli me tangere; nondum enim ascendi ad Patrem? Quod me vides, hominem solum putas, Patri aequalem esse adhuc nescis: noli me tangere talem, noli in hominem solum credere, sed Verbum aequale genitori intellege. Quid ergo est: Noli me tangere? Noli credere. Quid noli credere? Quia hoc solum sum quod vides ("¿Qué significa, pues: No me toques, pues aún no he subido al Padre? Piensas que soy sólo el hombre que ves; ignoras todavía que soy igual al Padre. No me toques de esta manera: no creas que soy solamente un hombre: piensa que soy la Palabra igual a quien me engendró. ¿Qué significa, pues: No me toques? «No creas». ¿Qué? "Que soy sólo lo que ves»"; trad. Pío de Luis, OSA); Tractatus 26.3: Quid est? Hoc solum me esse putas quod tibi appareo, noli sic credere ("¿Qué significa? Supones que yo soy sólo lo que aparezco ante ti; no creas así”; trad. por M. Fuertes Lanero y J. Anoz Gutiérrez). Ver también MArie-François Berrouard, Euvres de saint Augustin 75. Homélies sur l'Évangile de saint Jean CIV-CXXIV (Institut des Études Augustiniennes, Paris 2003) 86-87 y H. A. G. Houghton, Augustine's Text of John..., 351. 
pueda haber sido entendido también como una orden de dejar de hacer algo (en este pasaje, soltar a Jesús).

En cualquier caso, la opción de la Neovulgata de traducir iam noli me tenere utilizando una terminología no testimoniada por la tradición manuscrita es una muestra de la vitalidad permanente del texto y un ejemplo más de cómo el texto tiene capacidad de ser interpretado por la tradición. De manera análoga a lo que algunos traductores del Nuevo Testamento hicieron un siglo después de que se escribieran esos libros, lo han hecho los editores recientes de la Neovulgata, aunque en este caso por razones diversas a las de aquellos primeros.

\section{Conclusión}

A la luz de estos ejemplos y para concluir me gustaría tomar pie de lo que Parker comenta sobre el pasaje de la mujer sorprendida en adulterio, como pasaje paradigmático de lo que generalmente se entiende por una expansión del texto evangélico y que, por esta razón, ha sido eliminado de algunas ediciones modernas de la Biblia. El investigador de Birmingham sostiene que, a pesar de todos los problemas que presenta este pasaje, lo queramos o no, nos resulta imposible prescindir de él. Lo avala señalando que, así como muchas veces las variantes muestran que una forma textual está influida por otras, así sucede también con los pasajes que se consideran espurios. Y así como las seis formas textuales que él detecta en el Padrenuestro contribuyen -en su opinión- a comprender mejor la oración dominical sin que se pueda leer un supuesto texto original de este pasaje como si las otras formas no hubieran existido, así tampoco podemos prescindir de la historia de la mujer adúltera a la hora de leer los evangelios e incluso interpretar el Jesús histórico, como si esta historia no existiera. Además, en el caso de la mujer adúltera el relato tiene un atractivo al que no se puede ni se quiere renunciar. Y lo mismo podría decirse de las tradiciones sobre los magos o el buey y la mula en las narraciones de la infancia.

La tradición oral no es algo que acabó en cierto momento del siglo segundo, tercero o cuarto. El modo en que leemos el texto escrito es parte de toda la tradición que ha pasado de generación en generación ${ }^{63}$.

63 D. C. PARKER, The Living Text..., 102. 
En el caso del encuentro de Jesús con María, podemos pensar que la intención del evangelista era indicar que la Magdalena debía soltar a Jesús. Sin embargo, en nuestra comprensión no podremos evitar acercarnos a ese pasaje como si noli me tangere nunca hubiera existido. Tampoco podemos eliminar de nuestra imaginación las muchas representaciones pictóricas de esa escena. Algo semejante se puede decir del término Principium en el pasaje de Jn 8,25 y de los otros casos señalados. Como escribe Parker,

[1] a suma total de todo lo que hemos recibido de la tradición, escrita y oral [sin mencionar las posibles curiosidades recibidas como memoria heredada] es una parte del modo en que construimos nuestras interpretaciones, con independencia de nuestras decisiones sobre el valor histórico de los pasajes concretos ${ }^{64}$.

Sin duda, el concepto de tradición que maneja Parker no es el mismo que el que se utiliza al hablar de Escritura y tradición en ámbito teológico. Para él los manuscritos y sus alteraciones son testigos de un modo libre de entender el texto, como ejemplos de un texto que es "vivo" porque cambia. Desde el punto de vista teológico, en cambio, esas variantes son signos de la "tradición viva" que se daba en unas comunidades de fe, que entendían esos textos a la luz de la regula fidei. La variedad se toleraba si no infringía esa regla. Lo que importaba era el mensaje y ese mensaje podía enriquecerse con pequeñas variaciones. En este sentido cabría invocar las célebres palabras del Papa Gregorio Magno: divina eloquia cum legente crescunt ("las palabras divinas crecen con quien las leen") ${ }^{65}$. La lectura de la Palabra de Dios es un proceso que lleva a un crecimiento espiritual siempre adecuado a la situación del lector ${ }^{66}$. Las variantes textuales, en este caso de las traducciones, son manifestación de este crecimiento en la medida que nacen de la misma raíz y son expresión de la misma planta. El hecho de traducir, que no permite un trasvase exacto de lo que se dice en una lengua a otra, muestra cómo el texto bíblico no era concebido por los traductores como algo intocable escrito en el cielo por un ser divino.

64 D. C. Parker, The Living Text..., 102.

65 Gregorio, Hom. VII in Ezechielem, lib. I, 7.8 (CCL 142, 140; PL 76:843D).

66 Ver P. C. Bori, "Circolarità e sviluppo nell'interpretazione spirituale: «Divina eloquia cum legente crescunt» (Gregorio M, In Hiez. I,VII,8)”, en Annali di Storia dell'Esegesi 2 (1985) 263-274; ID., "Attualità di un detto antico? «La sacra Scrittura cresce con chi la legge»»", en Intersezioni 6 (1986) 15-49; ID., L'interpretazione infinita. L'ermeneutica cristiana e le sue trasformazioni (Il Mulino, Bologna 1987). 
Aunque no hubieran llevado a cabo una reflexión positiva sobre cómo se debía traducir, los que lo tradujeron tenían que enfrentarse a un texto que se presentaba con capacidad de ser entendido de diversas maneras dentro de los límites que establecía la regla de fe.

Como señala Piras, en el caso de la Vetus Latina los traductores no tenían todavía los recursos adecuados para traducir e interpretar el texto y se limitaban, sobre todo en los casos difíciles, a una traducción literal. Dejaban la interpretación de la Escritura a quienes gozaban de algún carisma especial. Eran conscientes de que tenían delante de ellos un texto en el que et uerborum ordo mysterium est ("hay un orden misterioso de las palabras") y donde singula nomina habent singula sacramenta: quot enim verba, tot mysteria ("todas palabras poseen un misterio propio"). ${ }^{67}$ No podían sacrificar ese misterio con arriesgadas interpretaciones de traducción. Por eso, si la Nueva Filología y el nuevo modo de hacer crítica textual invita a dar protagonismo a las variantes y a no encerrarlas en la prisión del aparato crítico, como decía Cerquiglini de manera exagerada, por la misma razón no parece que, en casos problemáticos, lo mejor sea encorsetar el texto en una traducción que limite en demasía las posibilidades de interpretación. A veces no será posible, pero al menos habrá que señalar humildemente que esa traducción es una entre otras posibles.

En todo caso, interpretar el texto requiere conocer el modo en que ha sido traducido, pues toda traducción es una interpretación. ${ }^{68}$ Pero no se debe olvidar que el texto que se traduce, por muy sofisticada que parezca la crítica textual, será como mucho el más cercano al texto original, evidentemente no el original. ${ }^{69}$ Este carácter "provisional" del

67 A. Piras, “Anastodeins, patei jah rodja du ižnis...”, 157-158. Las citas son de Jerónimo, Epistula 57; Ad Pammachium 7 y Tractatus in Psalmos 82,42-43. Se puede añadir también Agustín, Epistola 55,38: Sacramentum, aut aliquis sermo de sacris litteris.

68 Pontificia Comisión Bíblica, La interpretación de la Biblia en la Iglesia (15 abril 1993), IV, B: "Una traducción, en efecto, es siempre más que una simple trascripción del texto original. El paso de una lengua a otra comporta necesariamente un cambio de contexto cultural: los conceptos no son idénticos y el alcance de los símbolos es diferente, ya que ellos ponen en relación con otras tradiciones de pensamiento y otras maneras de vivir".

69 Así lo recuerda la PCB, La interpretación de la Biblia en la Iglesia..., I, A, 1, al hablar de las diversas etapas del método histórico-crítico. Al referirse a la crítica textual indica que busca "establecer un texto bíblico que sea el más cercano posible al texto original". 
texto tiene implicaciones teológicas importantes, también para no caer en una comprensión del cristianismo como "religión del libro". Cualquiera que haya sido la fluidez o -para evitar las connotaciones negativas que puede tener este término- la variación del texto neotestamentario (y con mayor razón el del Antiguo Testamento), las variantes ponen en guardia frente a un modo de hacer teología que parta de un texto "solidificado". La Palabra de Dios está testimoniada por diversos manuscritos, ninguno de ellos con garantías de trasmitir el texto que salió de la mano de un autor sagrado. En cambio, ya que el autor humano de la Biblia es también una comunidad creyente viva (Israel en su momento y el nuevo Israel, la Iglesia, después) el verdadero intérprete debe ser esa comunidad. Benedicto XVI lo afirma en la Exhortación Apostólica Verbum Domini: "El Libro es precisamente la voz del Pueblo de Dios peregrino, y sólo en la fe de este Pueblo estamos, por decirlo así, en la tonalidad adecuada para entender la Escritura". ${ }^{70}$ Precisamente, las traducciones tempranas de la Biblia manifiestan que el texto de esa comunidad podía ser actualizado en la comunidad viva de fe. El traductor antiguo consideraba "texto original" el texto que debía traducir, porque se leía in Ecclesia. ${ }^{71}$

Los problemas de crítica textual que aparecen en el texto y que, como se ha visto, están testimoniados en las traducciones ponen también de manifiesto la importancia de la oralidad en el proceso de interpretación. Se trata de un rasgo esencial a los orígenes cristianos, pero que nunca ha dejado de estar presente en la interpretación del texto bíblico. El sujeto de la tradición vive de unos textos, pero mantiene su vitalidad por medio de la tradición oral, como garante de la interpretación en la Iglesia. En este sentido, sirvan para concluir las siguientes palabras del entonces cardenal Ratzinger:

En el proceso de la exégesis crítica, sobre la naturaleza de la Palabra bíblica [...] se ha tomado conciencia de que la Palabra bíblica, en el

70 Benedicto XVI, Exhortación Apostólica Verbum Domini, n. 30.

71 Cf. J. CHAPA, "Texto autoritativo y crítica textual: Implicaciones teológicas del concepto «texto original» del Nuevo Testamento", en F. MiLÁn (ed.), Revelación, Escritura, Interpretación. Estudios en honor del Prof. D. Gonzalo Aranda Pérez. (Eunsa, Pamplona 2014) 153-176, aquí 170-176. Ver también las observaciones de V. Balaguer, "La Sagrada Escritura una cum Sacra Traditione ante el reto de la sola Scriptura", en Scripta Theologica 49 (2017) 171-192, sobre cómo los estudios históricos "muestran que lo que se transmite no es tanto una Escritura como objeto, cuanto una Escritura interpretada" (p. 192). 
momento de su fijación escrita, ya ha recorrido un proceso más o menos largo de configuración oral, y que, al ponerse por escrito, no ha quedado solidificada, sino que ha entrado en nuevos procesos de interpretación - relectures_, que han desarrollado ulteriormente sus potencialidades ocultas. La extensión, por tanto, del significado de la Palabra no puede quedar reducida al pensamiento de un autor singular de un determinado momento histórico. Más aún, la Palabra no pertenece a un único autor, sino que vive en una historia que progresa, y posee, por eso, una extensión y una profundidad hacia el pasado y hacia el futuro que finalmente se pierden en lo imprevisible ${ }^{72}$.

72 J. Ratzinger, "Discurso en la Investidura de Doctor «Honoris Causa» del cardenal Joseph Ratzinger en la Universidad de Navarra", en Scripta Theologica 30 (1998) 390 (original en castellano). * Este artículo es fruto del seminario organizado por la Asociación Bíblica Española e Asociación Bíblica Italiana en Roma el 2-3 de marzo de 2018. 


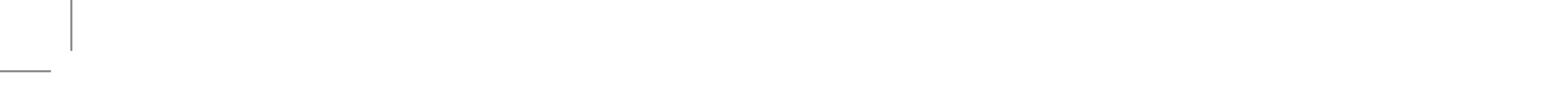

